\title{
Probing the Effect of Gaseous Hydrocarbon Precursors on the Adsorptive Efficiency of Synthesized Carbon-Based Nanomaterials
}

\author{
Haiyam Mohammed Alayan ${ }^{1, *}$, Mustafa Mohammed Aljumaily², \\ Mohammed Abdulhakim Alsaadi ${ }^{3}$, and Mohd Ali Hashim ${ }^{4}$ \\ ${ }^{1}$ Chemical Engineering Department, University of Technology, Baghdad, Iraq \\ ${ }^{2}$ Department of Civil Engineering, Al-Maaref University College, Ramadi, Iraq \\ ${ }^{3}$ National Chair of Materials Sciences and Metallurgy, \\ University of Nizwa, Nizwa, Sultanate of Oman \\ ${ }^{4}$ Chemical Engineering Department, University of Malaya, Kuala Lumpur, Malaysia
}

\begin{abstract}
The present work investigates the effect of the type of carbon precursor on the adsorptive proficiency of as-prepared carbon nanomaterials (CNMs) for the removal of methylene blue dye (MB) from aqueous media. A comparison study was applied to assess the growth of CNMs from the decomposition of methane (CNMY1) and acetylene (CNMY2) using response surface methodology with central composite design (RSM/CCD). The produced nanomaterials were characterized using FESEM, EDX, TEM, BET surface area, Raman, TGA, FTIR, and zeta potential. The as-prepared adsorbent displayed different morphologies and under the experimental conditions, $10 \mathrm{mg}$ of CNMY1 and CNMY2 was responsible for $97.7 \%$ and $96.80 \%$ removal of dye. The maximum adsorptive uptake predicted by Langmuir isotherm was about 250 and 174 $\mathrm{mg} / \mathrm{g}$ for CNMY1 and CNMY2, respectively. The as-synthesized carbon nanomaterial in this study could be explored as a great potential candidate for dye-bearing wastewater treatment.
\end{abstract}

Keywords: Adsorption; Carbon nanomaterials; Chemical vapor deposition; Dyes; Response surface methodology.

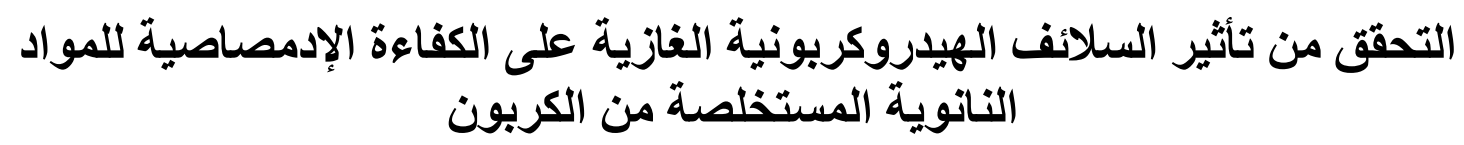

$$
\text { هيام محمد عليان *، مصطفى محمد الجميلي، محمد عبدالحكيم السعدي و محمد علي هاثم }
$$

الملخص: في هذه الورقة البحثية، تم تصنيع انابيب الكربون النانوية من نوعين مختلفين من الغازات الهيدركربونية

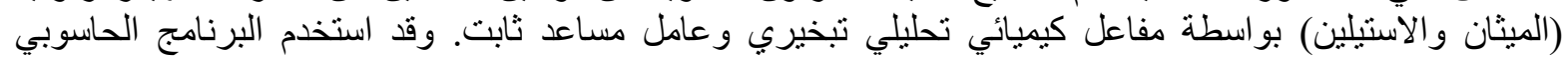

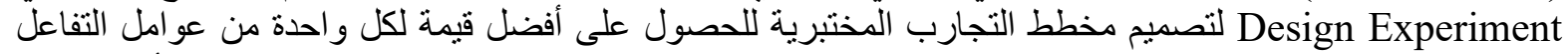

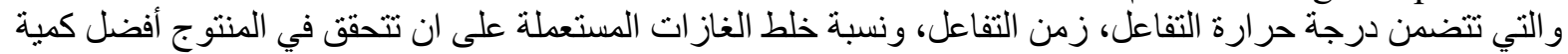

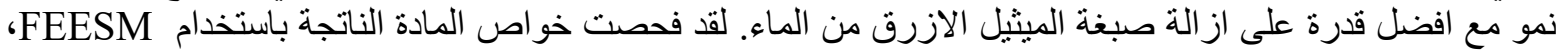

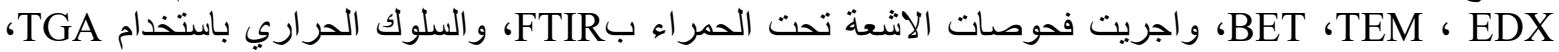

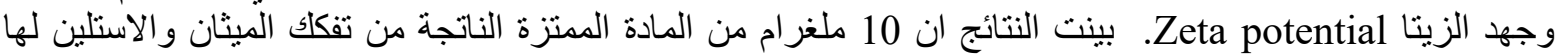

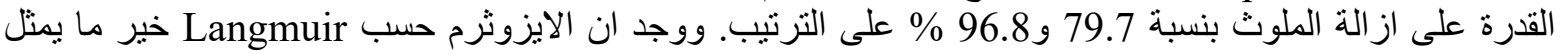

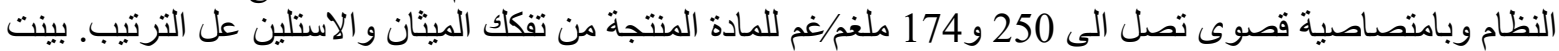

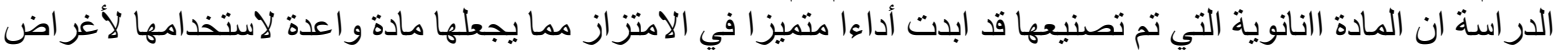

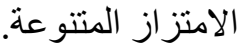

الكلمات الهفتاحية: الامتز از؛ انابيب كاربونية نانوية؛ مفاعل تبخيري ذو عامل مساعد؛ الاصباغ الملوثة.

*Corresponding author's e-mail: hayomchm@yahoo.com 


\section{INTRODUCTION}

Carbon nanomaterials (CNMs) have been intensively investigated for environmental applications due to their outstanding properties. They have enlightened different prospects as attractive sorbents for the removal of undesirable pollutants from water. Their high surface area, hybridized $s p^{2}$ carbon cluster and optimal binding efficiency enable strong adsorption capacity for organic contaminants (Hu et al. 2019; Sun et al. 2016).

Among the various techniques being used to synthesize CNMs, the chemical vapor deposition (CVD) is considered as the most promising technique, due to its versatility and suitability for large scale production. In CVD process and under tunable growth conditions, a statistical study should be conducted to achieve an adequate evaluation of the optimal growth conditions for CNMs, such as the utilized catalyst, carbon precursor type and flow rate, growth temperature and reaction time (Alayan et al. 2019; Gromov et al. 2016).

The agglomeration and ineffective recovery of CNMs are considered significant limitations which will confine their application in environmental remediation. Thus, it is essential to develop innovative adsorbents that can overcome the current challenges. Possible techniques proposed to resolve these drawbacks include centrifugation and attachment of magnetic nanoparticles. Nevertheless, both options will crucially add cost and complexity to the adsorption process. Accordingly, it is believed that growing carbon nanostructures on micro-scaled carbon support will enlighten the production of promising alternatives to the conventional adsorbents (Meshot et al. 2017).

Industrial effluents accept worrying quantities of colored pigments which impose harmful effects on the human health and surrounding ecosystems. Methylene blue (MB) contaminant has a potential danger of bioaccumulation due to its stability and low biodegradability, hence, efficient removal techniques of practical significance is imperative to remove it from industrial wastewaters before it is released to the environment. Of all treatment methods, adsorption based process has been widely implemented since it is simple, bear large volume of wastewater and devoid of utilizing organic solvents (Elsagh et al. 2017; Siddiqui et al. 2019).

In this work, we aim to assess the effect of hydrocarbon source being supplied in CVD reactor on the adsorption capacity of the as-prepared CNMs. Unlike previous studies that usually employ metallic substrates in the growth process of CNMs we fabricated our carbon nanomaterial by incorporating powder activated carbon (PAC) as analogues of noncarbon supports to boost the synergetic effect of hybridized CNMs to enhance their adsorptive affinity (Alayan et al. 2017). In this context, PAC was employed as a catalyst substrate to motivate the growth of CNMs from methane and acetylene decomposition. Response surface methodology with central composite design (RSM-CCD) technique was applied to optimize the preparation parameters followed by characterizing the as-prepared nanomaterial using EDX, BET, FESEM, TEM, Raman spectroscopy, TGA, FTIR, zeta potential and Goniometer. Later, the adsorption performance of the fabricated hierarchical CNMs was investigated for the removal of MB dye from water samples.

\section{MATERIALS AND METHODS}

\subsection{Materials}

Methylene blue, powder activated carbon, nickel (II) nitrate hexahydrate $\mathrm{Ni}\left(\mathrm{NO}_{3}\right)_{2} \cdot 6 \mathrm{H}_{2} \mathrm{O}$, were purchased from Sigma-Aldrich. Methane $\mathrm{CH}_{4}$, acetylene $\mathrm{C}_{2} \mathrm{H}_{2}$, hydrogen $\mathrm{H}_{2}$, nitrogen $\left(\mathrm{N}_{2}\right)$, were supplied in analytical grade and used without further purification.

\subsection{Synthesis of CNM/PAC using CVD}

A mixture of $2 \mathrm{~g}$ of dried PAC and $5 \mathrm{~mL}$ catalyst solution of nickel (II) nitrate hexahydrate (1.0 wt \%) was sonicated at $60^{\circ} \mathrm{C}$ for $1 \mathrm{~h}$. Then the $\mathrm{Ni}$ impregnated $\mathrm{PAC}$ was dried at $100^{\circ} \mathrm{C}$ overnight. The dried and grinded $\mathrm{Ni} / \mathrm{PAC}$ samples were exposed to two sequenced stages of thermal treatment in CVD reactor including calcination and reduction at 350 and $600{ }^{\circ} \mathrm{C}$ for 2 and $1 \mathrm{~h}$ under $200 \mathrm{~mL} / \mathrm{min}$ of $\mathrm{N}_{2}$ and $\mathrm{H}_{2}$. The growth of hierarchal CNM/PAC was achieved by shuffling a ceramic boat of the Ni/PAC into the reaction tube of CVD reactor. The growth process was conducted with the following conditions: $\mathrm{CH}_{4}$ and $\mathrm{H}_{2}$ were introduced to the CVD reactor at a ratio range of 1-4 within a temperature range of 750-1000 ${ }^{\circ} \mathrm{C}$ for 20 -60 min. Then the reactor was cooled and the produced CNMs were collected. The second hierarchal $\mathrm{CNM} / \mathrm{PAC}$ was synthesized from the decomposition of $\mathrm{C}_{2} \mathrm{H}_{2}$ following the same experimental procedure. However, in this case the growth reaction was conducted within the temperature range $550-750^{\circ} \mathrm{C}$. The yield of $\mathrm{CNMs}(\mathrm{CNMY})$ was calculated using equation (1):

Yield $=\frac{M_{2}-M_{1}}{\mathrm{M}_{1}}$

where $M_{2}$ and $M_{1}$ are the weight of the sample after and before reaction, respectively.

\subsection{Experimental Design and Optimization}

A design of experiment using CCD was employed to investigate how to obtain optimal growth parameters namely, hydrothermal temperature, reaction time and input gas ratio. The suggested regression model and the relevant statistical parameters were evaluated by the analysis of variance 
(ANOVA). Additionally, for optimization sake, maximizing the growth of CNMs was our response criterion. Accordingly, tridimensional plots were constructed to demonstrate the interaction between the underworking growth parameters.

\subsection{Characterization}

The PAC, Ni/PAC, and CNMs were dispersed onto copper grids to examine their surface morphologies using SEM equipped with Energy Dispersive X-Ray Spectroscopy and Transmission Electron Microscopy. Raman spectra and thermogravimetric analysis of CNMs were developed. The BET method was carried out to determine the surface area of the prepared nanomaterials. The FTIR spectra over the range 4000 to $400 \mathrm{~cm}^{-1}$ was used to analyze the surface changes. Surface charge analysis was investigated using the zeta potential measurements of a 0.01 wt $\%$ suspensions by Zetasizer. Finally, to debate the hydrophobicity issue, the goniometer was used to assess the surface hydrophobicity in terms of its contact angle.

\subsection{Measurements of Dye Performance}

The removal of $\mathrm{MB}$ on the as-prepared $\mathrm{CNMs}$ produced from the decomposition of $\mathrm{CH}_{4}$ and $\mathrm{C}_{2} \mathrm{H}_{2}$ were carried in a batch mode as follow: a fixed amount of each adsorbent $(10 \mathrm{mg})$ was agitated for $30 \mathrm{~min}$ at room temperature into the dye solution (50 $\mathrm{ml}$ ) at initial concentration of $50 \mathrm{mg} / \mathrm{L}$ and $\mathrm{pH} 11$. At the end of the adsorption experiments, the dye solution was centrifuged and the persisted concentration was determined using UV-vis spectroscopic at maximum wavelength $(665 \mathrm{~nm})$. The removal efficiency and the adsorbent uptake $(\mathrm{mg} / \mathrm{g})$ were calculated by the following relationships:

Removal Efficiency $(\%)=\frac{\mathrm{C}_{o}-\mathrm{C}_{\mathrm{e}}}{C_{o}} \times 100$

Uptake $=\frac{\mathrm{C}_{\mathrm{o}}-\mathrm{C}_{\mathrm{e}}}{\mathrm{W}} \times \mathrm{V}$

where $\mathrm{Co}$ and $\mathrm{Ce}(\mathrm{mg} / \mathrm{l})$ are the initial and equilibrium dye concentrations, respectively, $\mathrm{V}(\mathrm{L})$ is the volume the dye solution and $\mathrm{W}(\mathrm{g})$ is the amount of the adsorbent. The adsorption efficiency can be demonstrated via the analysis of experimental data to estimate the best fitted kinetic models and adsorption isotherms (Chen and Bai 2013). Kinetics of adsorption of $\mathrm{MB}$ on as-prepared $\mathrm{CNM}$ were investigated using both the pseudo-first-order and pseudo-second-order models. In addition, Langmuir and Freundlich isotherms were applied to study the sorbent-sorbate interactions.

\section{RESULTS AND DISCUSSION}

\subsection{Model Establishment and Statistical Analysis}

The growth temperature (A), growth time (B) and input gases flow ratio; $\left(\mathrm{H}_{2} / \mathrm{CH}_{4}\right)$ or $\left(\mathrm{H}_{2} / \mathrm{C}_{2} \mathrm{H}_{2}\right)$ (C) were optimized for $\mathrm{CNM} / \mathrm{PAC}$ synthesis using 2-level
CCD with one central point by the RSM/CCD method. The DOE software suggested conditions covered the growth temperature of $750-1000{ }^{\circ} \mathrm{C}, 550$ - $750{ }^{\circ} \mathrm{C}$ for $\mathrm{CH}_{4}$ and $\mathrm{C}_{2} \mathrm{H}_{2}$ decomposition, respectively. Also, for both hydrocarbon precursor, the reaction time and gases ratio were varied under the range of $20-60 \mathrm{~min}, 1.0-4.0$. The optimizing criterions were devoted to maximizing the yield percentage of CNMY1 and CNMY2 for $\mathrm{CH}_{4}$ and $\mathrm{C}_{2} \mathrm{H}_{2}$, respectively, while the independent parameters were kept in prescribed ranges.

The ANOVA summarized in Table 1 shows that the major determinants for CNMY1 obtained from $\mathrm{CH}_{4}$ decomposition are the growth temperature (A), the interaction of the growth temperature and the gas ratio (AC) and the second-order effect of growth temperature $\left(\mathrm{B}^{2}\right)$. The high model F-value and the low p- values $<0.05$ of these confirm their significance effect. The high correlation coefficient $\mathrm{R}^{2}$ value for CNMY1 and CNMY2 (>0.98) suggest that the

Table 1. ANOVA results for (CNMY1).

\begin{tabular}{|c|c|c|c|c|c|}
\hline *Source & $\begin{array}{l}\text { Sum of } \\
\text { Square }\end{array}$ & $d f$ & $\begin{array}{l}\text { Mean } \\
\text { Square }\end{array}$ & $F$-Value & $p$-value \\
\hline Model & 2.71 & 10 & 0.27 & 210.54 & 0.0005 \\
\hline A & 1.18 & 1 & 1.18 & 914.87 & $<0.0001$ \\
\hline B & 0.074 & 1 & 0.074 & 57.22 & 0.0048 \\
\hline $\mathrm{C}$ & 0.068 & 1 & 0.068 & 52.94 & 0.0054 \\
\hline $\mathrm{AB}$ & 0.11 & 1 & 0.11 & 84.02 & 0.0027 \\
\hline $\mathrm{AC}$ & 0.23 & 1 & 0.23 & 178.35 & 0.0009 \\
\hline $\mathrm{BC}$ & 0.0087 & 1 & 0.0087 & 6.76 & 0.0804 \\
\hline $\mathrm{A}^{2}$ & 0.009 & 1 & 0.009 & 69.48 & $<0.0036$ \\
\hline $\mathrm{B}^{2}$ & 0.043 & 1 & 0.043 & 33.05 & 0.0105 \\
\hline $\mathrm{C}^{2}$ & 0.0011 & 1 & 0.0011 & 0.89 & 0.4158 \\
\hline $\mathrm{A}^{2} \mathrm{C}$ & 0.048 & 1 & 0.048 & 37.40 & 0.0088 \\
\hline & \multicolumn{3}{|c|}{$\begin{array}{l}\text { R- Squared } 0.998 \\
\text { Adj. R-Squared } 0.994 \\
\text { Pred. R-Squared } 0.938\end{array}$} & \multicolumn{2}{|c|}{$\begin{array}{l}\text { Std.Dev. } 0.0359 \\
\text { C.V. } \% 1.35 \\
\text { precision } 46.61\end{array}$} \\
\hline $\mathrm{C}$ (feed & $\begin{array}{l}\text { emperatur } \\
\text { s flow rati }\end{array}$ & $\begin{array}{l}B(\mathrm{n} \\
): \mathrm{H}_{2} \\
\end{array}$ & $\begin{array}{l}\text { in): Tim } \\
\mathrm{CH}_{4}\end{array}$ & & \\
\hline
\end{tabular}

Table 2. ANOVA results for CNMY2.

\begin{tabular}{|c|c|c|c|c|c|}
\hline Source & $\begin{array}{l}\text { Sum of } \\
\text { Square }\end{array}$ & $d f$ & $\begin{array}{l}\text { Mean } \\
\text { Squar } \\
\text { e }\end{array}$ & $F$-Value & $p$-valuc \\
\hline Model & 0.692 & 8 & 0.0865 & 101 & 0.0098 \\
\hline A & 0.0176 & 1 & 0.0176 & 20.4 & 0.0456 \\
\hline B & 0.0522 & 1 & 0.0522 & 60.8 & 0.0160 \\
\hline $\mathrm{C}$ & 0.0334 & 1 & 0.0334 & 38.9 & 0.0247 \\
\hline $\mathrm{AB}$ & 0.0654 & 1 & 0.0654 & 76.1 & 0.0129 \\
\hline $\mathrm{AC}$ & 0.0921 & 1 & 0.0921 & 107.0 & 0.0092 \\
\hline $\mathrm{BC}$ & 0.231 & 1 & 0.231 & 269.0 . & 0.0037 \\
\hline $\mathrm{A} 2$ & 0.0197 & 1 & 0.0197 & 23.0 & 0.0409 \\
\hline A2 B & 0.0428 & 1 & 0.0428 & 49.9 & 0.0195 \\
\hline & $\begin{array}{l}\text { R- Squa } \\
\text { Adj. R-S } \\
\text { Pred. R- }\end{array}$ & $\begin{array}{l}\text { d } 0.9 \\
\text { uare } \\
\text { quare }\end{array}$ & $\begin{array}{l}8 \\
0.988 \\
0.929\end{array}$ & \multicolumn{2}{|c|}{ C.V. \% 0.604} \\
\hline $\begin{array}{l}{ }^{*} \mathrm{~A}\left({ }^{\circ} \mathrm{C}\right) \\
\mathrm{C}(\text { feed }\end{array}$ & $\begin{array}{l}\text { Temperat } \\
\text { gas flow } \mathrm{r}\end{array}$ & $\begin{array}{l}\text { re, } B \\
\text { io): }\end{array}$ & $\begin{array}{l}\min ): \mathrm{T} \\
/ \mathrm{C}_{2} \mathrm{H}_{2}\end{array}$ & & \\
\hline
\end{tabular}



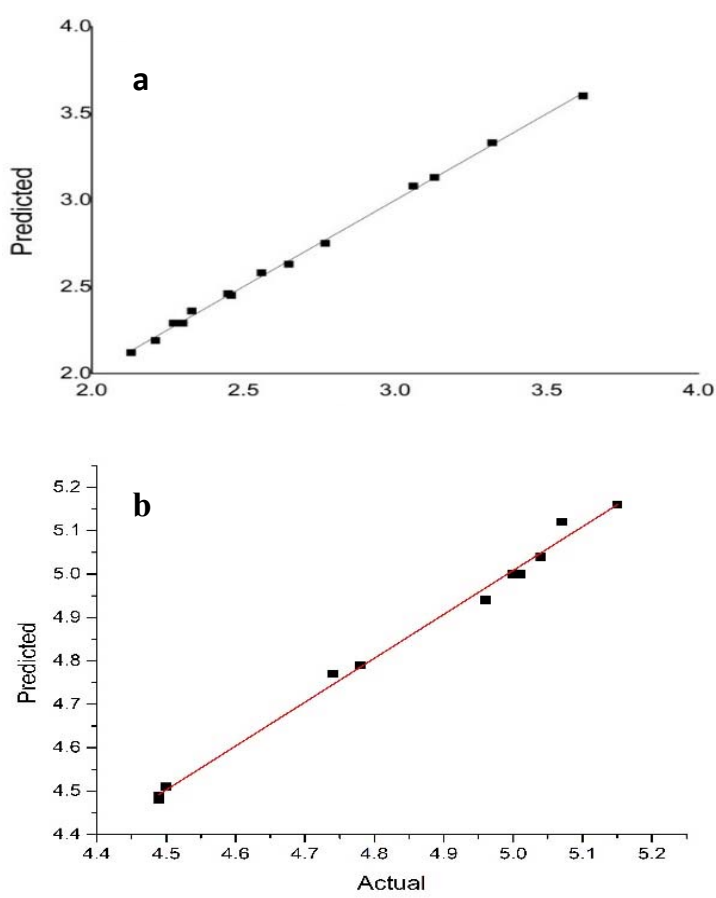

Figure 1. Predicted vs. actual values; (a) CNMY1, (b) CNMY2.

Table 3. The optimum conditions suggested by DOE for CNMY1.

\begin{tabular}{lllllll}
\hline No. & A & B & C & CNMY1\% & \multicolumn{2}{l}{ Desirability } \\
\hline 1 & 950 & 60.0 & 1.00 & 36.7 & 0.989 & $\checkmark$ \\
2 & 950 & 59.8 & 1.00 & 36.5 & 0.986 & \\
3 & 950 & 60.0 & 1.00 & 36.5 & 0.986 & \\
4 & 950 & 60.0 & 1.03 & 36.4 & 0.984 & \\
5 & 950 & 59.7 & 1.00 & 36.3 & 0.982 & \\
6 & 950 & 60.0 & 1.13 & 35.7 & 0.970 & \\
7 & 950 & 60.0 & 1.22 & 35.1 & 0.959 & \\
8 & 950 & 60.0 & 1.00 & 33.4 & 0.927 & \\
9 & 950 & 60.0 & 1.52 & 33.0 & 0.917 & \\
10 & 950 & 20.0 & 1.00 & 23.0 & 0.674 & \\
\hline
\end{tabular}

Table 4. The optimum conditions suggested by DOE for CNMY2.

\begin{tabular}{lllllll}
\hline \multicolumn{1}{c}{ CN } & A & B & C & CNMY2 \% & \multicolumn{2}{c}{ Desirability } \\
\hline 1 & 560 & 38.0 & 1.00 & 154.47 & 0.919 & $\checkmark$ \\
2 & 561 & 38.0 & 1.00 & 152.9 & 0.916 & \\
3 & 560 & 38.5 & 1.00 & 154.47 & 0.914 & \\
4 & 560 & 38.0 & 1.12 & 152.9 & 0.913 & \\
5 & 561 & 38.4 & 1.00 & 154.47 & 0.912 & \\
\hline
\end{tabular}

obtained model offers a successful correlation between the growth variables and good estimation of the responses which is confirmed by the plots of their predicted values against the actual values presented in Fig. 1a and 1b. Furthermore, the statistical results in Table 2 support the significance of the suggested model for CNMY2 from $\mathrm{C}_{2} \mathrm{H}_{2}$ pyrolysis for the linear terms (A), (B), and (C). The interaction effect of (AC) and $(\mathrm{BC})$ displayed p-values of 0.009 and 0.0036, respectively indicating their strong impact over the studied range as well. The regression equation for CNMY1 and CNMY2 in terms of their actual values are given by equations (4) and (5):

Ln $C N M Y 1=-11.4+0.0304 A+0.0789 B+11.0 C+$ $5.79 \times 10^{-5} A B-0.0251 A C-0.0011 B C-$

$1.45 \times 10^{-5} A^{2}+0.00046 B^{2}+0.0128 C^{2}+$

$1.41 \times 10^{-5} A^{2} C$

Ln $C N M Y 2=26.0-0.0637 A-0.385 B-0.28+$ $0.00121 A B+0.000715 A C-0.00566 B C+$

$4.59 \times 10^{-5} A^{2}-8.96 \times 10^{-7} A^{2} B$

\subsubsection{Response Surface Methodology}

The effect of the substantial factors and the feature of the obtained response surface in the experiment were examined by using RSM/CCD. The interaction effects of the process parameters on CNMY1 and CNMY2 based on the empirical model were illustrated by RSM plots. Fig. 2 displayed an outstanding increase in CNMY1 with increasing the reaction temperature from 750 to $950^{\circ} \mathrm{C}$, implying the favor of high reaction temperature for the growth of CNMs Fig. 2a. There was no significant improvement for CNMY1with the increase in $(\mathrm{H} 2 / \mathrm{CH} 4)$, since high concentration of $\mathrm{H} 2$ will motivate the backward reaction thus reducing the yield of CNMY1 Fig. 2b. Also, the CNMY1 improved with increasing growth time and then dropped as the reaction proceeds Fig. 2c. This decrease in the yield of the CNMs at long reaction period is attributed to the catalyst deactivation due to the formation of amorphous carbon. In Fig. 3a, increasing reaction temperature from 550 to $650^{\circ} \mathrm{C}$ has a distinguished improvement on the throughput of CNMY2 at fixed $\mathrm{H} 2 / \mathrm{C} 2 \mathrm{H} 2$ (1.0) which is in agreement with the role of PAC substrate in minimizing the deactivation of impregnated catalyst even at high growth temperatures (Tao and Crozier 2016). However, an increase in CNMY2 for low reaction temperatures and $\mathrm{H} 2 / \mathrm{C} 2 \mathrm{H} 2$ at fixed reaction time is observed in Fig. 3b, and the high temperature accompanying with high gas flow ratio was unfavorable for CNMY2. This might be since the high $\mathrm{H} 2$ content will accelerate the reduction of metal oxides which in turn encourages the deposition of pyrolytic carbons on the catalytic sites. Moreover, it can be noticed from Fig. $3 \mathrm{c}$ that at short reaction time the yield of CNNMY2 was high and almost the same at $\mathrm{H} 2 / \mathrm{C} 2 \mathrm{H} 2$ of 1.0 and 4.0 which indicates the insignificance effect of the gas ratio. This observation motivates the production of CNMs at small reaction periods to get high yield and prevent catalyst deactivation as well (Shen et al. 2016). 


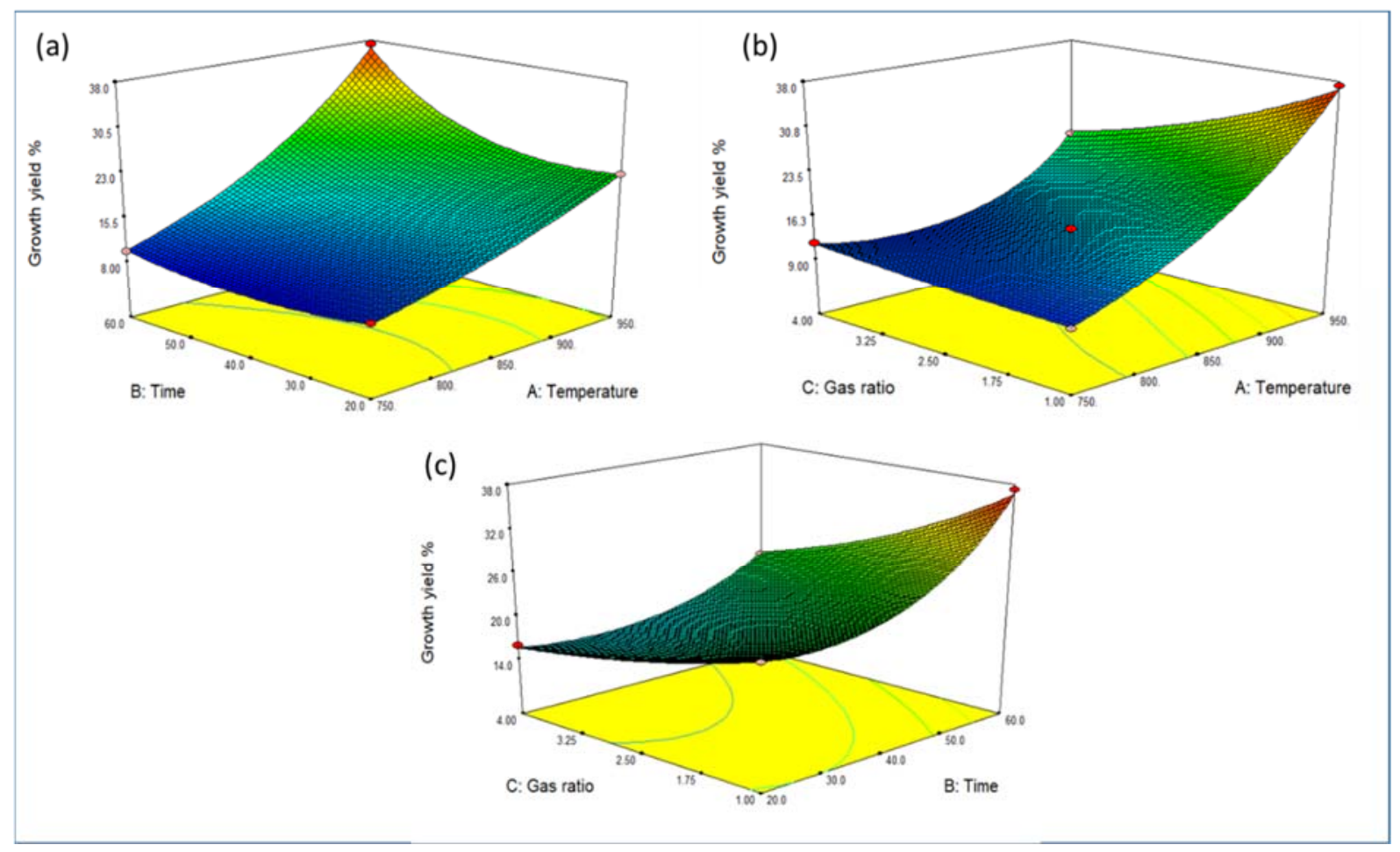

Figure 2. Response surface illustration of the interaction effects on CNMY1: (a) growth temperature and time, (b) growth temperature and gas ratio and (c) time and gas ratio.

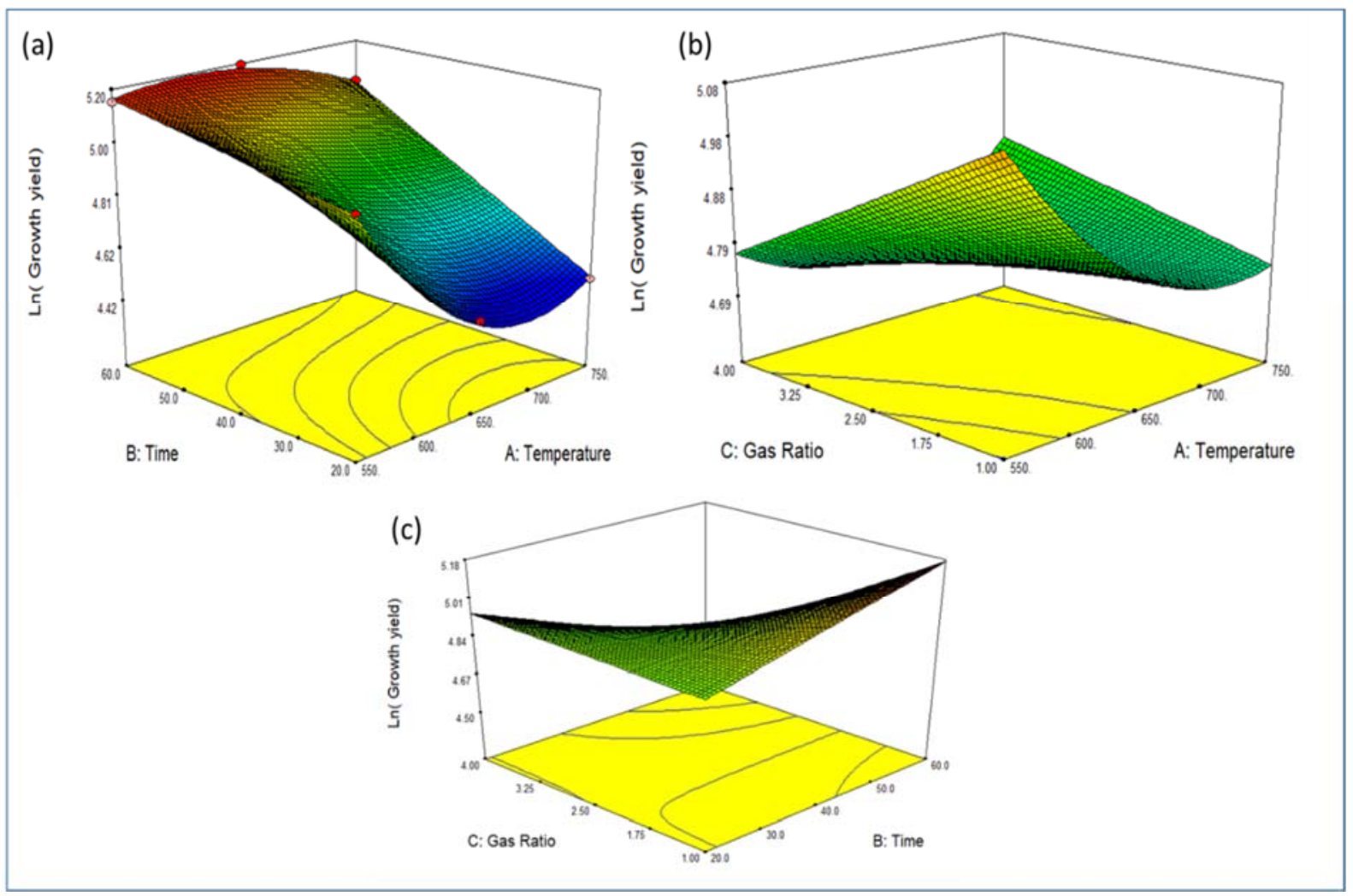

Figure 3. Response surface illustration of interaction effects on CNMY2: (a) growth temperature and time, (b) growth temperature and gas ratio and (c) time and gas ratio. 

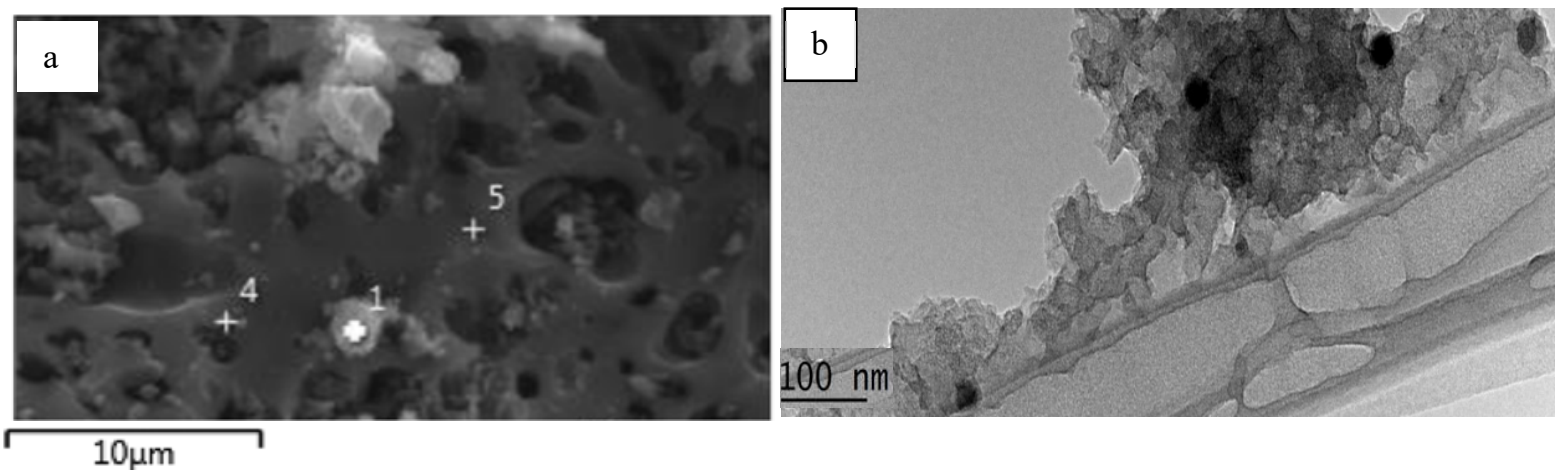

$10 \mu \mathrm{m}$

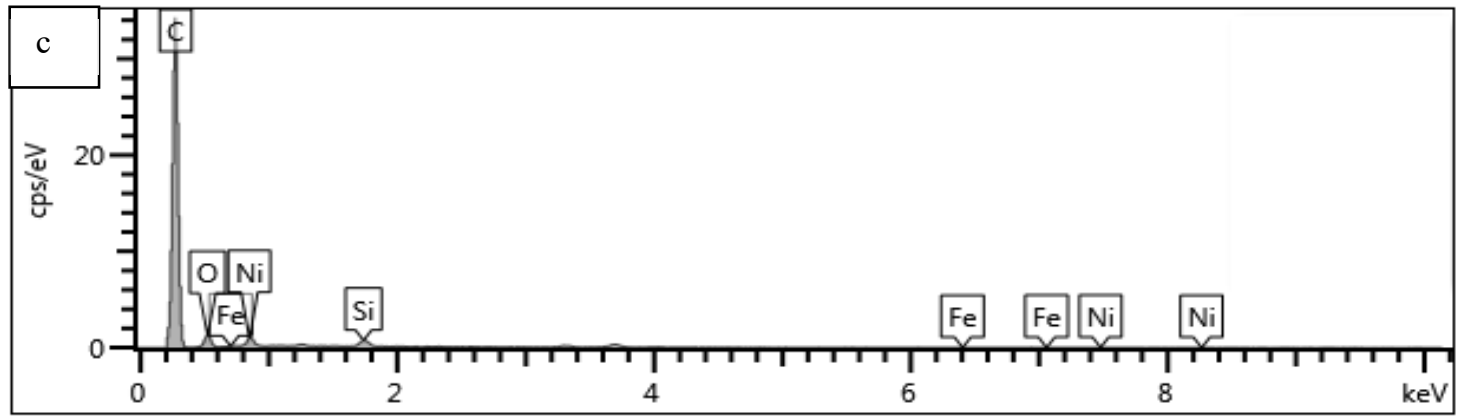

Figure 4. (a) FESEM, (b) TEM and (c) EDX images for Ni/PAC before the growth reaction.
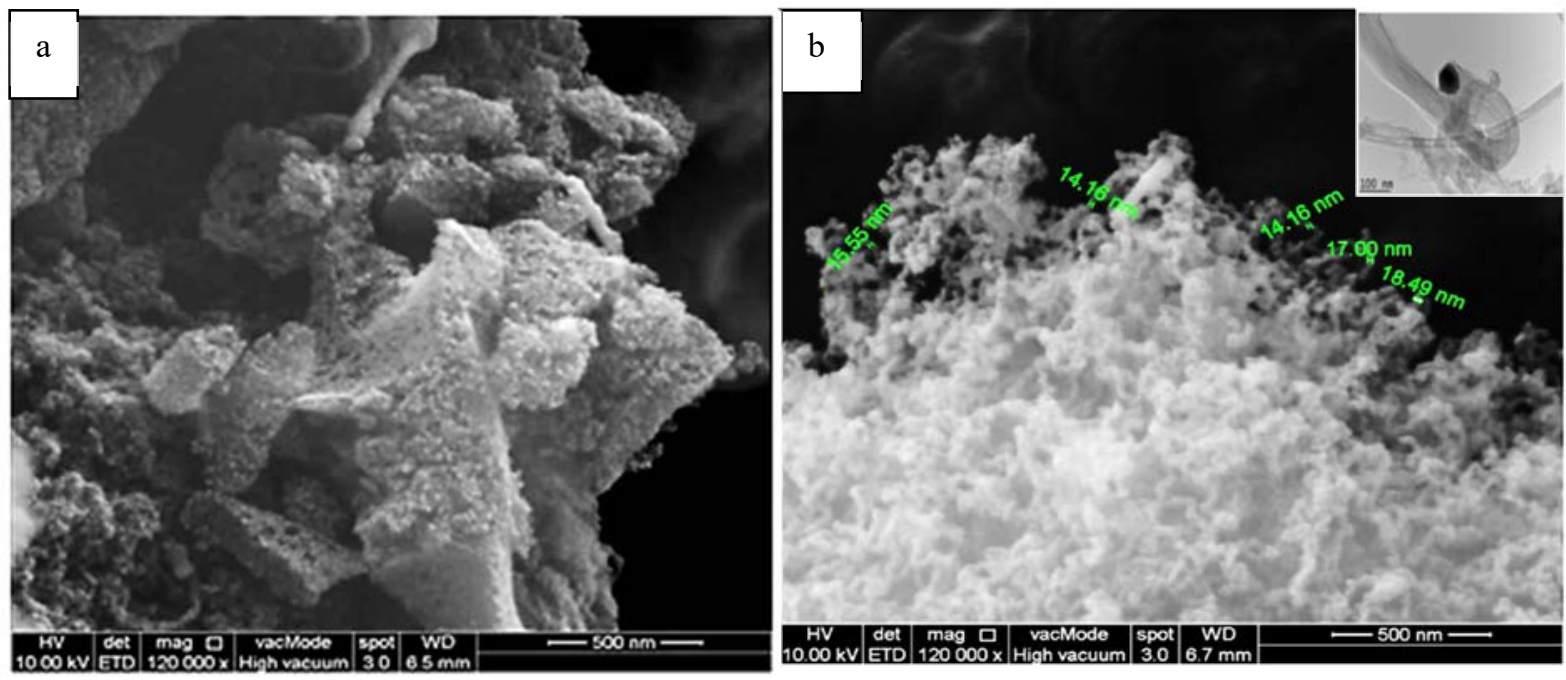

Figure 5. FESEM images of (a) CNMY1 and (b) CNMY2 obtained at optimal conditions.

\subsubsection{Optimization Study}

Numerical optimization was applied to determine the optimal growth conditions for $\mathrm{CH}_{4}$ and $\mathrm{C}_{2} \mathrm{H}_{2}$ decomposition. Thus, the predefined criterions for the optimal working conditions were applied by keeping the synthesis parameters within the prescribed upper and lower limits of the growth conditions in order to achieve the maximum yield and the highest desirability value which will confirm the adequacy of the predicted models. Table 3 indicated that the predicted optimum conditions for CNMY1 were $950^{\circ} \mathrm{C}, 60 \mathrm{~min}$, and 1.0 corresponding to growth temperature, growth time and $\mathrm{H}_{2} / \mathrm{CH}_{4}$, respectively leading to yield $\sim 37.0 \%$. A yield of $\sim 155 \%$ for
CNMY2 was obtained at the optimal conditions of a $560^{\circ} \mathrm{C}, 38 \mathrm{~min}$ and $1.0 \mathrm{H}_{2} / \mathrm{C}_{2} \mathrm{H}_{2}$ (Table 4).

\subsection{Characterization 3.2.1 Morphology}

The FESEM and TEM images of the nickel-doped activated carbon (Ni/PAC) show a successful imbedding for the catalyst particles in the pores of PAC substrate (Fig. 4a and 4b). The elemental analysis attained from EDX (Fig. 4c) shows that the loaded substrate is comprised of $88.58 \mathrm{wt} \%$ carbon, $7.48 \mathrm{wt} \%$ oxygen, $\mathrm{wt} \% 3.26 \mathrm{wt} \%$ nickel and 0.67 $\mathrm{wt} \%$ silicon. The growth of various types of CNMs 
from this low catalyst amount validates the catalyzing role of PAC and its ability to provide good media for catalyst dispersion (Li et al. 2014).

Fig. 5 shows the morphologies of hierarchical nanomaterial shaped from the methane (CNMY1$\left.\mathrm{CH}_{4}\right)$ and acetylene $\left(\mathrm{CNMY} 1-\mathrm{C}_{2} \mathrm{H}_{2}\right)$ decomposition at the optimal growth conditions. The hybrid CNMY1$\mathrm{CH}_{4}$ displayed in Fig. 5a has groove-like form and resemble the PAC porous structures. CNMY1- $\mathrm{CH}_{4}$ hybrid is comprised from short interposed carbon nanotubes (CNTs) which are randomly oriented in the substrate matrix and embedded on the solid walls of the pores the activates carbon substrate. The hybrid CNMY $1-\mathrm{C}_{2} \mathrm{H}_{2}$ in Fig. $5 \mathrm{~b}$ and $5 \mathrm{c}$, which was obtained at the optimal synthesis conditions, show bushy and graphitized tubular structures of CNTs with 10-40 $\mathrm{nm}$, and an intercalated catalytic nickel nanoparticle (CNP) which was separated from the substrate and confined at the tip of the grown CNT. This observation suggests a tip growth mechanism for the CNT which triggered by the precipitation of the generated carbon fragments on the $\mathrm{Ni}$ surface followed by the growth of the tube and terminated finally due to the catalyst deactivation (Jeong et al. 2016).

\subsubsection{TGA Analysis}

The TGA analysis in Fig. 7 assesses the quality and thermal stability of CNMY1 and CNMY2 obtained from $\mathrm{CH}_{4}$ and $\mathrm{C}_{2} \mathrm{H}_{2}$. The TGA profile can be highlighted by the initial gradual loss due to moisture evaporation of $2.0 \%$ and $5.0 \%$ followed by constant drops to the onset combustion temperature at 507 and $455^{\circ} \mathrm{C}$ for CNMY1 and CNMY2, respectively. The third region was featured by a steep drop region and ended with the oxidization section of the remaining amorphous carbon at temperature higher than $500{ }^{\circ} \mathrm{C}$. Additionally, a well-graphitized structure for CNMY1 is obtained and confirmed by its high onset temperature. The TGA analysis indicates that the produced carbon nanostructures from both hydrocarbon precursor sustain a temperature as high as $800{ }^{\circ} \mathrm{C}$ (Zhou et al. 2014).

\subsubsection{BET Surface Area}

The surface area of the PAC, Ni/PAC, CNMY1 and CNMY2 was determined by nitrogen adsorptiondesorption measurements. The results illustrated in Table 5 show a reduction in the surface area of $\mathrm{Ni} / \mathrm{PAC}$ due to the catalyst impregnation. Furthermore, an enhancement in the surface area of the obtained hybrids CNMY1 and CNMY2 because the added structure on the substrate. The total pore volume of CNMY1 and CNMY2 reached $0.29 \mathrm{~cm}^{3} / \mathrm{g}$ and 0.44 , respectively. This logical result can be ascribed to the development of new micropores resulting from the growth of different nanostructures on the substrate which will be beneficial for improving the adsorbent sorption capacity (Wang et al. 2017).

\subsubsection{Raman Analysis}

Raman analysis displayed in Fig. 7 for the CNMY1 and CNMY2 detected the main D and G characteristic band. The D peak at around $1316 \mathrm{~cm}^{-1}$ suggests the presence of disordered graphite structure while the $\mathrm{C}-\mathrm{C}$ stretching vibration is characterized by the $\mathrm{G}$ band at around $1594 \mathrm{~cm}^{-1}$. The high intensity of $\mathrm{D}$ band confirms the defective nature of the obtained structure due to the thermal treatment step. Also, the grown hybrids involved multiwall structure confirmed by the disappearance of the radial breathing mode (RBM) at wavelength below $400 \mathrm{~cm}^{-1}$ (Ahmad et al. 2018). The organizational degree of the obtained hybrids can be represented by $\mathrm{I}_{\mathrm{D}} / \mathrm{I}_{\mathrm{G}}$ and it is noticed that synthesized nanocarbon structure ratio was 0.9 and 0.82 from the decomposition of $\mathrm{CH}_{4}$ and $\mathrm{C}_{2} \mathrm{H}_{2}$, respectively. This indicates that the decomposition of $\mathrm{C}_{2} \mathrm{H}_{2}$ enhanced the growth of highly graphitized nanostructure which was also observed in the TGA analysis. Also, the CNMs synthesized from acetylene pyrolysis at $750^{\circ} \mathrm{C}$ demonstrated $\mathrm{I}_{\mathrm{D}} / \mathrm{I}_{\mathrm{G}}$ ratio of 0.74 which suggests a lesser graphitic structure than that obtained at $560^{\circ} \mathrm{C}$.

\subsubsection{FTIR Analysis}

The functional group and surface chemistry of CNMY1 and CNMY2 synthesized at the optimal growth conditions were presented in the FTIR spectroscopy in Fig. 8. Absorption bands at 3450$3500 \mathrm{~cm}^{-1}$ assigned to the $-\mathrm{OH}$ group. The ascribed peaks from the $\mathrm{Ni}$ catalyst carbonyl were found at 1979 and $2138 \mathrm{~cm}^{-1}$ (Chavan et al. 2012), whereas the peak emerged at $\sim 2350 \mathrm{~cm}^{-1}$ is attributed to the presence of aromatic $s p^{2} \mathrm{C}-\mathrm{H}$ stretching vibration. The aromatic rings and $\mathrm{C}=\mathrm{C}$ stretch were appeared at 1447 and $1563 \mathrm{~cm}^{-1}$, respectively. It is observed that the CNMY2 hybrids has fewer functional groups than that produced from $\mathrm{CH}_{4}$ decomposition, accordingly higher hydrophobicity is expected for CNMY2 (Ezzeddine et al. 2016)

\subsubsection{Zeta Potential and Contact Angle}

The adsorption mechanism is greatly affected by the surface charge and the hydrophobicity of the adsorbent (Aljumaily et al. 2018). Ni/PAC is not a hydrophobic material and its cast film a contact angle of $65^{\circ}$ as presented in Table 6 .

The CNMY1 has lower zeta potential than that obtained for CNMY2.The surface positive charge and basicity of CNMY1 could be due to the oxygen-free carbon sites ( $\pi$ - electron-rich regions) located in the basal planes. Furthermore, the CNMY1 hybrids show enhanced hydrophobicity associated with high contact angle of $138^{\circ}$ but lower than that obtained for CNMY2. The super hydrophobic CNMs synthesized from acetylene decomposition demonstrated high contact angle of $160^{\circ}$ with high value of zeta potential due to the mutual repulsion of CNMs surface charges. 


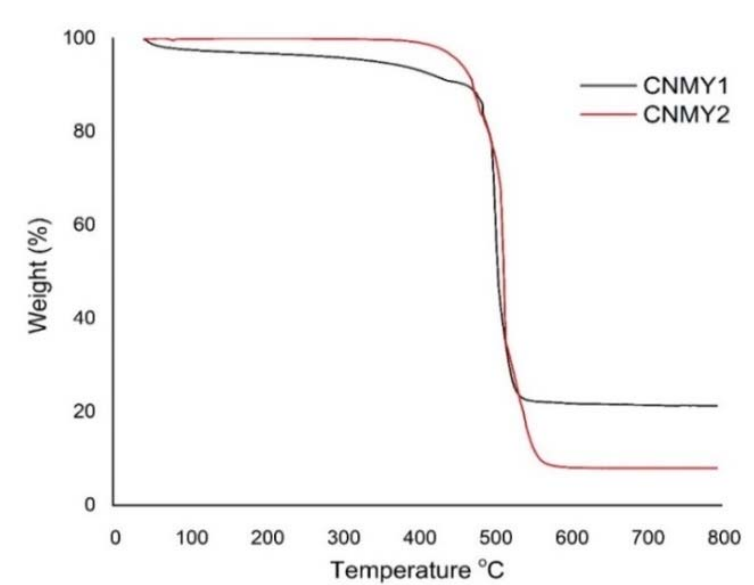

Figure 6. TGA curves for CNMY1 and CNMY2.

Table 5. BET results of PAC, Ni/PAC, CNMY1 and CNMY2.

\begin{tabular}{|c|c|c|c|c|}
\hline Property & PAC & Ni/PAC & $\begin{array}{l}\text { CNM } \\
\text { Y1 }\end{array}$ & $\begin{array}{l}\text { CNM } \\
\text { Y2 }\end{array}$ \\
\hline $\operatorname{BET}\left(\mathrm{m}^{2} / \mathrm{g}\right)$ & 101.1 & 97.2 & 164.6 & 333.83 \\
\hline $\begin{array}{l}\text { Total pore } \\
\text { volume }\left(\mathrm{cm}^{3} / \mathrm{g}\right)\end{array}$ & 0.09 & 0.07 & 0.29 & 0.44 \\
\hline $\begin{array}{l}\text { Average pore } \\
\text { diameter }\left({ }^{\circ} \mathrm{A}\right)\end{array}$ & 34.89 & 21.29 & 96.19 & 65.09 \\
\hline
\end{tabular}

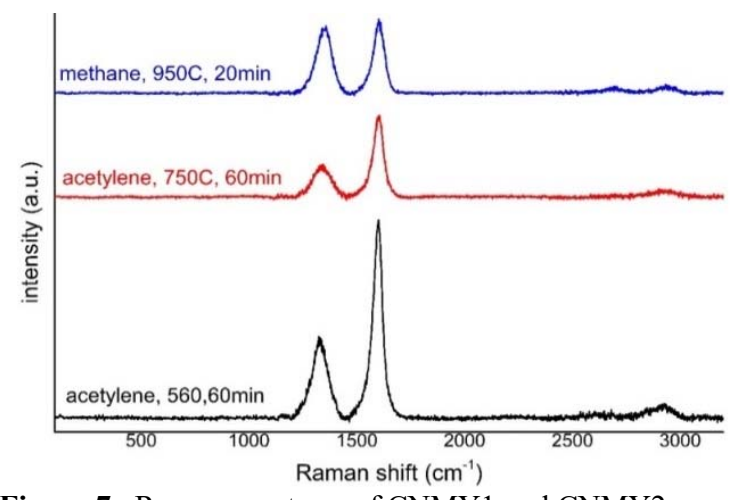

Figure 7. Raman spectrum of CNMY1 and CNMY2.

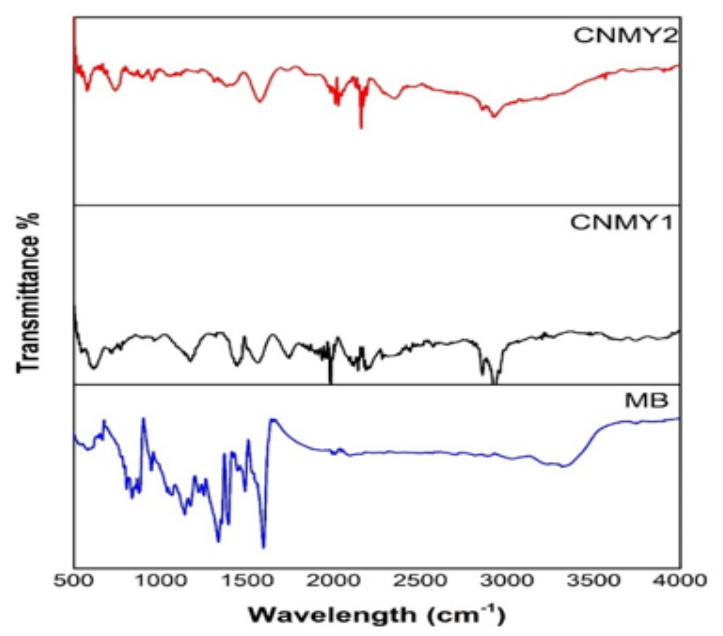

Figure 8. FTIR spectrums for free MB, CNMY1 and CNMY2 after adsorption.

\subsubsection{Kinetics and Isotherm Studies}

Two models were applied to analyze the kinetic data obtained from the batch experiments of $\mathrm{MB}$ adsorption on CNMY1 and CNMY2: pseudo-first order, and pseudo-second models (Fig. 9). The relevant parameters derived from the corresponding equations are provided in Table 7 , imply that the adsorption process has not entirely followed the pseudo first-order rate expression for both adsorbents (Fig. 9a and 9b). In contrast, the applicability of the pseudo-second-order model better to describe the sorption kinetics of MB dye is clearly observed in Fig. $9 \mathrm{c}$ and $9 \mathrm{~d}$ confirmed by the high correlation coefficient of the linear plots. This observation suggests the possibility of chemisorption adsorption mechanism through exchange or sharing electrons between the adsorbent and adsorbate (Subramani and Thinakaran 2017). For the isotherm study, the favorability of the Langmuir isotherm can be conveniently represented by the equilibrium parameter $\left(\mathrm{R}_{\mathrm{L}}\right) ;\left(0<\mathrm{R}_{\mathrm{L}}<1\right)$ which is defined by equation (6).

$$
\mathrm{R}_{\mathrm{L}}=\frac{1}{1+\mathrm{K}_{\mathrm{L}} C_{o}}
$$

The values summarized in Table 8 and the linear plots presented in Fig. 10 agreed well with the Langmuir isotherm (Model 1) for CNMY1 and CNMY2 signifying monolayer adsorption with heterogeneous surface binding, however, sorption capacity values of CNMY2 was conveniently described by Freundlich model (Model 2) as well. This kind of duality has been stated in many publications (Wang et al. 2014). Comparison of the maximum adsorption uptake of $\mathrm{MB}$ on several adsorbents are presented in Table 9. The as-prepared hybrid carbon nanomaterials in the present work have demonstrated noteworthy adsorption uptake of 250 and $174 \mathrm{mg} / \mathrm{g}$ for CNMY1 and CNMY2, respectively.

Table 6. Zeta potential results for $\mathrm{Ni} / \mathrm{PAC}$ and the obtained carbon structures.

\begin{tabular}{lcc}
\multicolumn{2}{c}{ Carbon structures. } \\
\hline Sample & $\begin{array}{c}\text { Zeta potential } \\
(\mathbf{m V})\end{array}$ & $\begin{array}{c}\text { Contact angle }\left({ }^{\circ}\right) \\
\text { Ni/PAC }\end{array}$ \\
CNMY1 $\left(950^{\circ} \mathrm{C}\right)$ & +1.67 & 65 \\
CNMY2 $\left(560^{\circ} \mathrm{C}\right)$ & -34.3 & 138 \\
\hline
\end{tabular}


Table 7. Experimental values of kinetics model's constants.

$$
\text { Model }
$$

Pseudo-First-Order

$$
\ln \left(q_{e}-\mathrm{q}_{\mathrm{t}}\right)=\ln q_{e}-K_{1} \mathrm{t}
$$

$$
\frac{t}{q_{t}}=\frac{1}{K_{2} q_{e}^{2}}+\frac{1}{q_{e}} t
$$

Pseudo-Second-Order

\section{Parameters}

\begin{tabular}{c} 
Values \\
\hline CNMY1
\end{tabular}

$R^{2}$

$K_{1}$

$q_{e}$

0.83

0.02

27.0

0.89

0.03

38.9

\begin{tabular}{|c|c|c|c|c|}
\hline \multirow[t]{2}{*}{ Model } & \multirow[t]{2}{*}{$\overline{\text { Equation }}$} & \multirow[t]{2}{*}{ Parameters } & \multicolumn{2}{|c|}{ Values } \\
\hline & & & CNMY1 & CNMY2 \\
\hline \multirow[t]{4}{*}{ Langmuir } & & $q_{m}$ & 250.0 & 174.0 \\
\hline & $\underline{C_{e}}=\underline{1}+(\underline{1}) C_{e}$ & $K_{L}$ & 0.65 & 1.5 \\
\hline & $q_{e} \quad K_{L} q_{m} \quad\left(q_{m}\right)^{v_{e}}$ & $R^{2}$ & 0.98 & 0.99 \\
\hline & & $R_{L}$ & 0.03 & 0.01 \\
\hline \multirow[t]{3}{*}{ Freundlich } & 1 & $R^{2}$ & 0.86 & 0.93 \\
\hline & $\ln q_{e}=\ln K_{f}+\frac{-}{n} \ln C_{e}$ & $K_{f}$ & 85.0 & 83.7 \\
\hline & & $\mathrm{n}$ & 2.8 & 2.6 \\
\hline
\end{tabular}

$\begin{array}{ccc}R^{2} & 0.999 & 0.99 \\ K_{1} & 0.002 & 0.0015 \\ q_{e} & 145.0 & 122.7\end{array}$

Table 8. Linearized equations of studied isotherm models.

\begin{tabular}{|c|c|c|}
\hline Adsorbent & $q_{m}(\mathrm{mg} / \mathrm{g})$ & Reference \\
\hline CNMY1 & 250 & The present work \\
\hline CNMY2 & 174 & The present work \\
\hline MWCNTs & 109.31 & (Zohre et al. 2010) \\
\hline Activated carbon & 123 & (Suresh et al. 2011) \\
\hline MWCNTs by CVD (acetylene, Fe/Si) & 50.25 & (Liu et al. 2014) \\
\hline Cotton stalk & 147.06 & (Deng et al. 2011) \\
\hline Graphene/magnetite & 43.08 & (Ai et al. 2011) \\
\hline Oxidized-CNTs & 99.83 & (Norzilah et al. 2011) \\
\hline Calcined titanate NT & 133.33 & (Xiong et al. 2010) \\
\hline MWCNTs & 59.7 & (Wang et al. 2012) \\
\hline $\mathrm{Fe}_{3} \mathrm{O}_{4}-\mathrm{MWCNTs}\left(\mathrm{HNO}_{3}\right)$ & 48.06 & (Ai et al. 2011) \\
\hline
\end{tabular}

Table 9. maximum adsorption uptake (qm) comparison with previous studies. 
Probing the Effect of Gaseous Hydrocarbon Precursors on the Adsorptive Efficiency

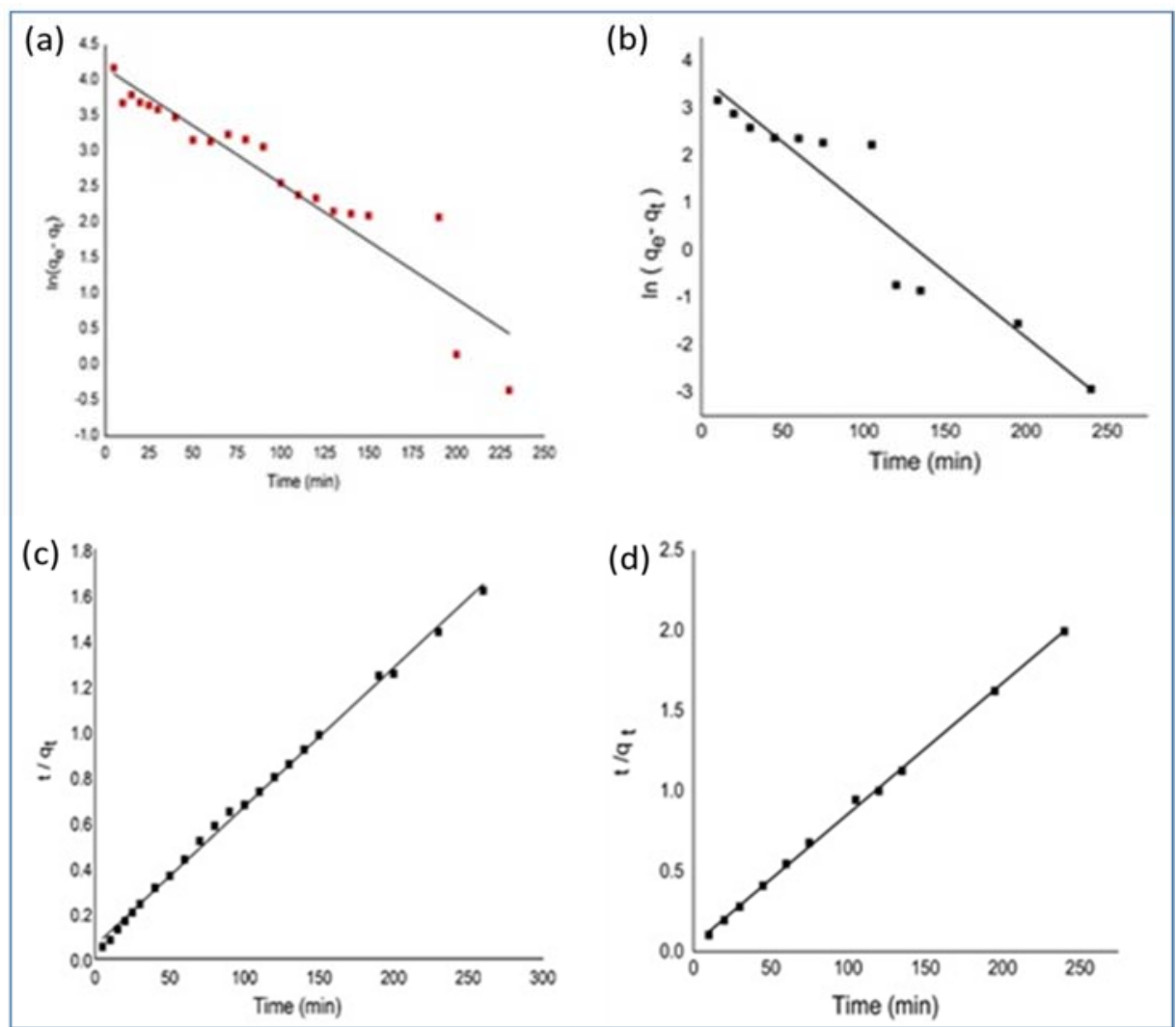

Figure 9. Fittings of Pseudo-first order and Pseudo-second order kinetics models for MB adsorption on CNMY1 (a, b) and CNMY2 (c, d), respectively.
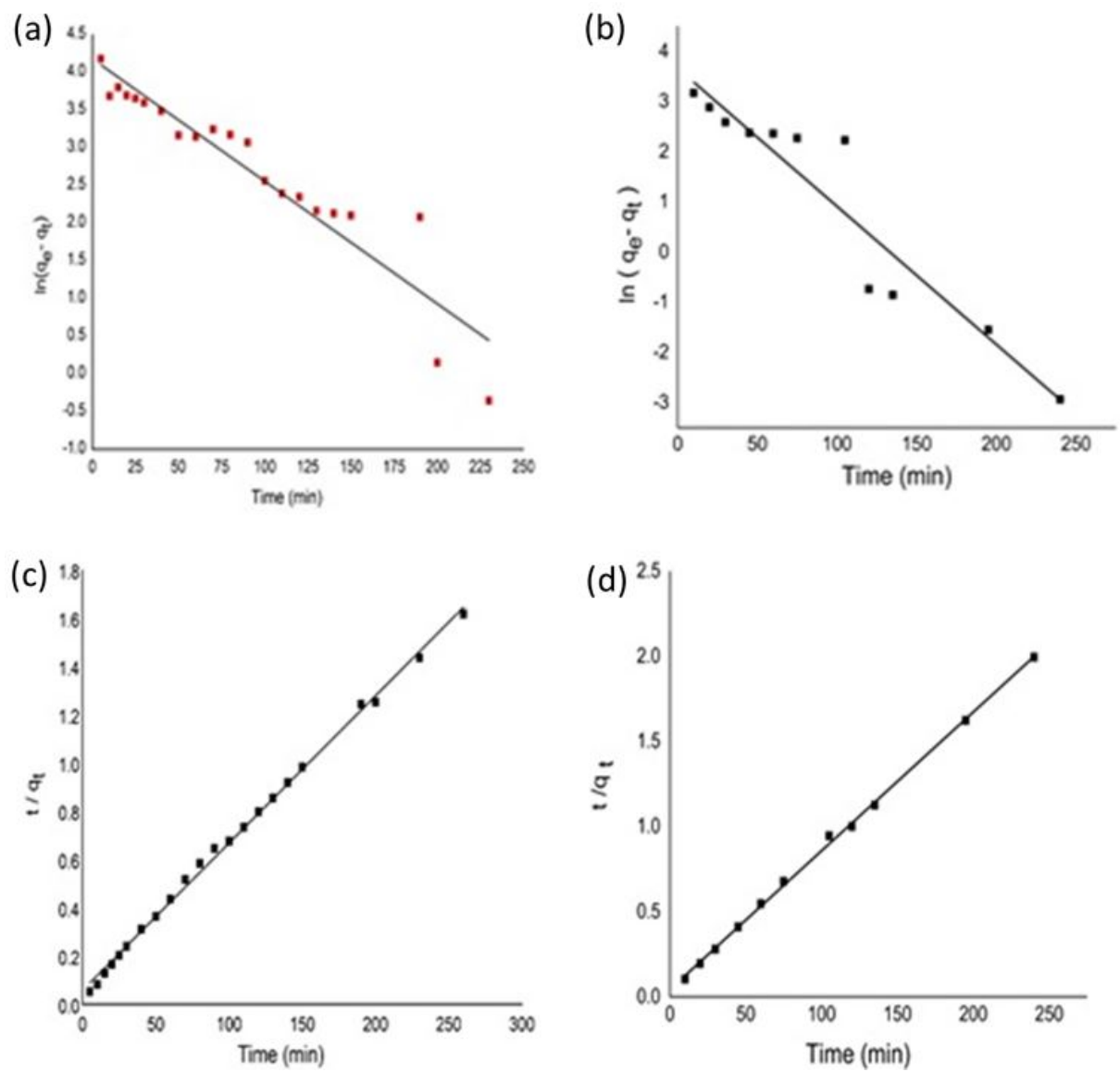

Figure 10. Langmuir and Freundlich model plots for MB adsorption on CNMY1 (a,b) and CNMY2 (c,d), respectively. 


\section{CONCLUSION}

The growth of CNMs from different precursors and optimizing their growth parameters were investigated. The optimal growth conditions for the hybrid carbon nanomaterials obtained from methane and acetylene were found at the temperature of 950 , $60, \mathrm{H} 2 / \mathrm{CH} 4$ of 1.0 and $560{ }^{\circ} \mathrm{C}$, time of $38 \mathrm{~min}$, and $\mathrm{H} 2 / \mathrm{C} 2 \mathrm{H} 2$ of 1.0 , respectively. Undoubtedly, the carbon source played a significant role to affect the morphology of CNMs deposits due to discrepancies in their pyrolytic behaviors. Methane has the simplest chemical structure and comparatively stable at hightemperature than acetylene. Also, the Gibbs free energies of the $\mathrm{C} 2 \mathrm{H} 2$ has lower decomposition temperature than methane which gives rise to lower growth temperature of CNMs. The MB removal process on each adsorbent was fitted well to a pseudosecond order kinetics model and the adsorption system was excellently presented by Langmuir isotherm model with a maximum adsorption capacity of 250 and $174 \mathrm{mg} / \mathrm{g}$ for CNM/PAC-CH4 and $\mathrm{CNM} / \mathrm{PAC}-\mathrm{C} 2 \mathrm{H} 2$, respectively.

\section{CONFLICT OF INTEREST}

The authors declare no conflicts of interest.

\section{ACKNOWLEDGMENT}

The authors would like to acknowledge the University of Malaya Research Grant UMRG (RP034D-15AET) and University of Technology - Iraq for funding this research.

\section{REFERENCES}

Ahmad, A., Razali, M. H., Kassim, K., and Amin, K. A. M. (2018). "Synthesis of multiwalled carbon nanotubes supported on M/MCM-41 $(\mathrm{M}=\mathrm{Ni}$, Co and $\mathrm{Fe}$ ) mesoporous catalyst by chemical vapour deposition method." Journal of Porous Materials, 25(2), 433-441.

Ai, L., Zhang, C., and Chen, Z. (2011). "Removal of methylene blue from aqueous solution by a solvothermal-synthesized graphene/magnetite composite." Journal of hazardous materials, 192(3), 1515-1524.

Ai, L., Zhang, C., Liao, F., Wang, Y., Li, M., Meng, L., and Jiang, J. (2011). "Removal of methylene blue from aqueous solution with magnetite loaded multi-wall carbon nanotube: kinetic, isotherm and mechanism analysis." Journal of hazardous materials, 198, 282-290.

Alayan, H. M., Alsaadi, M. A., Abo-Hamad, A., AlOmar, M. K., Aljumaily, M. M., Das, R., and Hashim, M. A. (2017). "Hybridizing carbon nanomaterial with powder activated carbon for an efficient removal of Bisphenol A from water: the optimum growth and adsorption conditions." DESALINATION AND WATER TREATMENT, 95, 128-143.

Alayan, H. M., Alsaadi, M. A., AlOmar, M. K., and Hashim, M. A. (2019). "Growth and optimization of carbon nanotubes in powder activated carbon for an efficient removal of methylene blue from aqueous solution." Environmental technology, 40(18), 2400-2415.

Aljumaily, M. M., Alsaadi, M. A., Das, R., Hamid, S. B. A., Hashim, N. A., AlOmar, M. K., Alayan, H. M., Novikov, M., Alsalhy, Q. F., and Hashim, M. A. (2018). "Optimization of the synthesis of superhydrophobic carbon nanomaterials by chemical vapor deposition." Scientific reports, 8(1), 2778.

Chavan, S., Vitillo, J. G., Larabi, C., Quadrelli, E. A., Dietzel, P. D., and Bordiga, S. (2012). "Functionalization of CPO-27-Ni through metal hexacarbonyls: The role of open $\mathrm{Ni} 2+$ sites."Microporous and mesoporous materials, 157, 56-61.

Chen, L., and Bai, B. (2013). "Equilibrium, kinetic, thermodynamic, and in situ regeneration studies about methylene blue adsorption by the raspberrylike TiO2@yeast microspheres." Industrial \& Engineering Chemistry Research, 52(44), 1556815577.

Deng, H., Lu, J., Li, G., Zhang, G., and Wang, X. (2011). "Adsorption of methylene blue on adsorbent materials produced from cotton stalk." Chemical Engineering Journal, 172(1), 326-334.

Elsagh, A., Moradi, O., Fakhri, A., Najafi, F., Alizadeh, R., and Haddadi, V. (2017). "Evaluation of the potential cationic dye removal using adsorption by graphene and carbon nanotubes as adsorbents surfaces." Arabian Journal of Chemistry, 10, S2862-S2869.

Ezzeddine, Z., Batonneau-Gener, I., Pouilloux, Y., and Hamad, H. (2016). "Removal of methylene blue by mesoporous CMK-3: Kinetics, isotherms and thermodynamics." Journal of Molecular Liquids, 223(Supplement C), 763-770.

Gromov, D. G., Bulyarskii, S., Pavlov, A., Scorik, S., Shulyat'ev, A., and Trifonov, A. Y. (2016). "Catalytic CVD-growth of array of multiwall carbon nanotubes on initially amorphous film $\mathrm{Co}-$ $\mathrm{Zr}-\mathrm{N}-\mathrm{O} . "$ Diamond and Related Materials, 64(Supplement C), 97-102.

Hu, C., Lin, Y., Connell, J. W., Cheng, H. M., Gogotsi, Y., Titirici, M. M., and Dai, L. (2019). "Carbon-Based Metal-Free Catalysts for Energy Storage and Environmental Remediation." Advanced Materials, 31(13), 1806128.

Jeong, S., Lee, J., Kim, H.-C., Hwang, J. Y., Ku, B.C., Zakharov, D. N., Maruyama, B., Stach, E. A., and Kim, S. M. (2016). "Direct observation of morphological evolution of a catalyst during carbon nanotube forest growth: new insights into growth and growth termination." Nanoscale, 8(4), 
2055-2062.

Li, Y.-h., Gao, H.-q., Yang, J.-h., Gao, W.-1., Xiang, J., and Li, Q.-y. (2014). "Multi-wall carbon nanotubes supported on carbon fiber paper synthesized by simple chemical vapor deposition." Materials Science and Engineering: B, 187, 113119.

Liu, Y., Kang, Y., Mu, B., and Wang, A. (2014). "Attapulgite/bentonite interactions for methylene blue adsorption characteristics from aqueous solution." Chemical Engineering Journal, 237, 403-410.

Meshot, E. R., Zwissler, D. W., Bui, N., Kuykendall, T. R., Wang, C., Hexemer, A., Wu, K. J. J., and Fornasiero, F. (2017). "Quantifying the Hierarchical Order in Self-Aligned Carbon Nanotubes from Atomic to Micrometer Scale." ACS nano.

Norzilah, A., Fakhru'l-Razi, A., Choong, T. S., and Chuah, A. L. (2011). "Surface modification effects on CNTs adsorption of methylene blue and phenol." Journal of Nanomaterials, 2011, 55.

Shen, K., Chen, X., Chen, J., and Li, Y. (2016). "Development of MOF-derived carbon-based nanomaterials for efficient catalysis." ACS Catalysis, 6(9), 5887-5903.

Siddiqui, S. I., Fatima, B., Tara, N., Rathi, G., and Chaudhry, S. A. (2019). "Recent advances in remediation of synthetic dyes from wastewaters using sustainable and low-cost adsorbents." The Impact and Prospects of Green Chemistry for Textile Technology, Elsevier, 471-507.

Subramani, S., and Thinakaran, N. (2017). "Isotherm, kinetic and thermodynamic studies on the adsorption behaviour of textile dyes onto chitosan." Process Safety and Environmental Protection, 106, 1-10.

Sun, D. L., Hong, R. Y., Liu, J. Y., Wang, F., and Wang, Y. F. (2016). "Preparation of carbon nanomaterials using two-group arc discharge plasma." Chemical Engineering Journal, 303, $217-$ 230.

Suresh, S., Sugumar, R. W., and Maiyalagan, T. (2011). "Equilibrium and Kinetic studies on the adsorption of Methylene blue from aqueous solution onto activated carbon prepared from Murraya koenigii (curry tree) stems." Asian Journal of Chemistry, 23(10), 4486.

Tao, F., and Crozier, P. A. (2016). "Atomic-scale observations of catalyst structures under reaction conditions and during catalysis." Chemical reviews, 116(6), 3487-3539.

Wang, C., Yang, S., Ma, Q., Jia, X., and Ma, P.-C. (2017). "Preparation of carbon nanotubes/graphene hybrid aerogel and its application for the adsorption of organic compounds." Carbon, 118, 765-771.

Wang, J., Chen, Z., and Chen, B. (2014). "Adsorption of polycyclic aromatic hydrocarbons by graphene and graphene oxide nanosheets." Environmental science \& technology, 48(9), 4817-4825.

Wang, S., Ng, C. W., Wang, W., Li, Q., and Hao, Z. (2012). "Synergistic and competitive adsorption of organic dyes on multiwalled carbon nanotubes." Chemical engineering journal, 197, 34-40.

Xiong, L., Yang, Y., Mai, J., Sun, W., Zhang, C., Wei, D., Chen, Q., and Ni, J. (2010). "Adsorption behavior of methylene blue onto titanate nanotubes." Chemical Engineering Journal, 156(2), 313-320.

Zhou, L., Ji, L., Ma, P.-C., Shao, Y., Zhang, H., Gao, W., and Li, Y. (2014). "Development of carbon nanotubes/CoFe $2 \mathrm{O} 4$ magnetic hybrid material for removal of tetrabromobisphenol $\mathrm{A}$ and $\mathrm{Pb}$ (II)." Journal of hazardous materials, 265, 104114.

Zohre, S., Ataallah, S. G., and Mehdi, A. (2010). "Experimental study of methylene blue adsorption from aqueous solutions onto carbon nano tubes." International Journal of Water Resources and Environmental Engineering, 2 (2), 016 -028. 